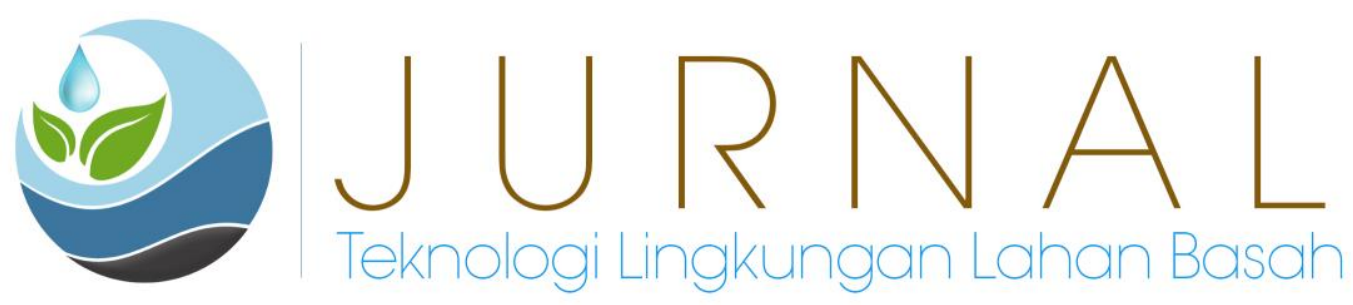

\title{
Pemanfaatan Limbah Tulang Ikan Tongkol (Euthynnusaffinis C) dari Home Industry Abon sebagai Tepung
}

\author{
Edo Septiansyah ${ }^{1}$, Oggi Agustiandi Putra ${ }^{1}$, Khairul Abshar ${ }^{1}$, Dian Rahayu Jati ${ }^{1}$, dan Isna \\ Apriani ${ }^{1}$ \\ ${ }^{1}$ Jurusan Teknik Lingkungan, Universitas Tanjungpura, Pontianak \\ E-mail : edoseptiansyah44@gmail.com
}

\begin{abstract}
Waste minimization is an effort to reduce the volume, concentration, toxicity, and hazard level of waste originating from the production process by reducing its source and / or utilizing waste. Shredded fish is a processed product in the form of fine and dry fish meat fiber where the manufacturing process is a combination of boiling and frying by adding spices. The amount of industrial production of tuna shredded typical of Pontianak every Saturday and Sunday can reach 5-10 kg (depending on the order) with attractive packaging which is sold for IDR 50,000 per 200 grams. In processing tuna shredded it produces waste such as head, bones, tail, skin, and entrails. The minimization of waste that is carried out is the waste of fish bones produced by shredded fish which is used to become flour which contains lots of calcium.
\end{abstract}

Keywords: Clean Technology, Fish Bone Flour, Shredded Fish Waste, Tongkol Fish, and Waste Minimization

Abstrak

Minimisasi limbah adalah suatu upaya untuk mengurangi volume, konsentrasi, toksisitas, dan tingkat bahaya limbah yang berasal dari proses produksi, dengan jalan reduksi pada sumbemya dan atau pemanfaatan limbah. Abon ikan adalah hasil olahan berupa serat daging ikan yang halus dan kering dimana proses pembuatannya merupakan kombinasi antara perebusan dan penggorengan dengan melakukan penambahan bumbu. Jumlah produksi Industri Abon ikan tongkol khas Pontianak setiap hari sabtu dan minggu bisa mencapai $5-10 \mathrm{~kg}$ (tergantung pesanan) dengan kemasan menarik yang dijual Rp50 ribu per 200 gram.Dalam Pengolahan abon ikan tongkol tersebut menghasilkan limbah seperti kepala,tulang,ekor, kulit, dan isi perut. Minimisasi limbah yang dilakukan adalah Limbah tulang ikan hasil produksi abon dimanfaatkan menjadi tepung yang banyak mengandung kalsium.

Kata Kunci : Ikan Tongkol, Limbah Abon Ikan, Minimasi Limbah, Teknologi Bersih dan Tepung Tulang Ikan 


\section{PENDAHULUAN}

Kekayaan produktivitas ikan laut yang dimiliki Indonesia sebesar 2.752.838 ton pada tahun 2006, dengan jumlah produksi ikan laut terbesar berasal dari jenis ikan tongkol sekitar $31,2 \%$, cakalang $26,9 \%$, tenggiri $17,2 \%$, cucut $14,1 \%$, dan ikan jenis lainnya $10,7 \%$. Dari data tersebut, didapatkan rata-rata per tahun untuk produktivitas ikan di indonesia mengalamai kenaikan pada jenis ikan tongkol 5,5\%. Konsumsi ikan saat ini meningkat di kalangan masyarakat, tentunya mengakibatkan perkembangan usaha terutama industri perikanan juga terus mengalami pertumbuhan dengan signifikan. Sehingga pembuangan hasil produksi industri perikanan tidak terkendali dan belum dimanfaatkan dengan benar. Hasil pembuangan limbah industri perikanan mempunyai berbagai macam jenis seperti tulang, kepala, sisik, ekor, jeroan, dan kulit ikan (Aninda dkk., 2010).

Industri perikanan sebagian besar limbahnya dibuang begitu saja tanpa adanya proses penanganan lebih lanjut, dengan hal tersebut perlu adanya inovasi untuk mengolah limbah lebih optimal menjadi bermanfaat tanpa mengotori atau mencemari lingkungan disekitarnya. Mengatasi hal tersebut, terdapat beberapa inovasi seperti limbah industri perikanan menjadi bahan tambahan di dalam proses produksi pangan. Inovasi tersebut dengan memanfaatkan limbah tulang ikan. Limbah tulang ikan selalu banyak dan terbuang dengan sia-sia tanpa diolah dengan baik (Dewi dan Akyhunul, 2008).

Pemanfaatan limbah tulang ikan dapat berupa pembuatan tepung. Tepung yang berasal dari tulang ikan tersebut mengandung kalsium dan kalsium fosfor yang tinggi di antara kalsium lain (Lestari, 2001). Prevalensi osteoporosis di Indonesia cukup tinggi, yaitu mencapai 53.6\% pada kelompok wanita dan 34\% pada kelompok pria di atas 70 tahun, dan 18-36\% pada wanita dan 20-27\% pada pria di bawah usia 70 tahun (Rachman dan Setiyohadi, 2007). Hal tersebut tidak terlepas dari kebiasaan konsumsi pangan sumber kalsium di kalangan masyarakat Indonesia yang masih rendah. Manusia dewasa membutuhkan asupan kalsium 500-800 $\mathrm{mg}$ /hari, kalsium yang dibutuhkan untuk berbagai fungsi dalam tubug seperti pembentukan tulang dan gigi, katalisator reaksi biologis dan kontraksi otot (Mulia, 2004).

Tepung dari tulang ikan ini dapat membantu proses pengembalian atau penyembuhan gangguan pertumbuhan, tulang kurang kuat, bengkok, dan rapuh, yang dinamakan osteoporosis. Sehingga tepung tulang ikan ini merupakan inovasi baru untuk mengatasi permasalahan tersebut, walaupun sumber kalsium yang paling sering masyarakat ketahui adalah susu dan suplemen kalsium. Akan tetapi, daya beli rata-rata masyarakat indonesia pada umumnya tidak mampu untuk mendapatkan susu dan suplemen kalsium tersebut.

Jenis ikan tongkol dan ikan tenggiri merupakan sumberdaya ikan pelagis yang mempunyai nilai ekonomis yang tinggi bagi masyarakat di indonesia dan sebagai komoditi ekspor (Zulfahmi et al., 2014). Hal tersebut, diakibatkan kandungan gizi yang melimpah dari kedua jenis ikan tersebut. Kebanyakan orang hanya memanfaatkan daging kedua jenis ikan tersebut untuk dikonsumsi, tapi tidak memanfaatkan sisa pembuangan dari kedua jenis ikan tersebut. Oleh karena itu terdapat inovasi untuk mengatasi hal tersebut dengan memanfaatkan limbah tulang ikan tongkol sebagai bahan baku pembuatan tepung yang mempunyai potensi terdapat gizi dan kalsium yang tinggi serta tidak kalah saing dengan susu dan suplemen kalsium. 


\section{METODE PENELITIAN}

Lokasi "Home industry abon ikan tongkol istimewa khas pontianak" berada di jalan Gusti Hamzah, gg. Pancasila IV, Kota Pontianak, Kalimantan Barat. Penelitian ini dilakukan pada tanggal 10 September 2020 dengan proses awal wawancara dengan pemilik usaha abon dan identifikasi proses produksi pembuatan abon dari ikan tongkol. Selanjutnya, identifikasi kendala yang dipengaruhi oleh beberapa aspek yaitu proses produksi, bahan baku, teknologi, tata laksana, produk, dan limbah sehingga menghasilkan alternatif penerapan produksi bersih untuk mengurangi dan menanggulangi limbah yang dihasilkan. Dalam penelitian ini terdapat perlakuan kontrol dan perlakuan eksperimen sebagai acuan antara keadaan awal dengan keadaan setelah diberi perlakuan. Teknik pengumpulan data yang dilakukan dalam penelitian ini adalah menggunakan metode observasi dan wawancara.

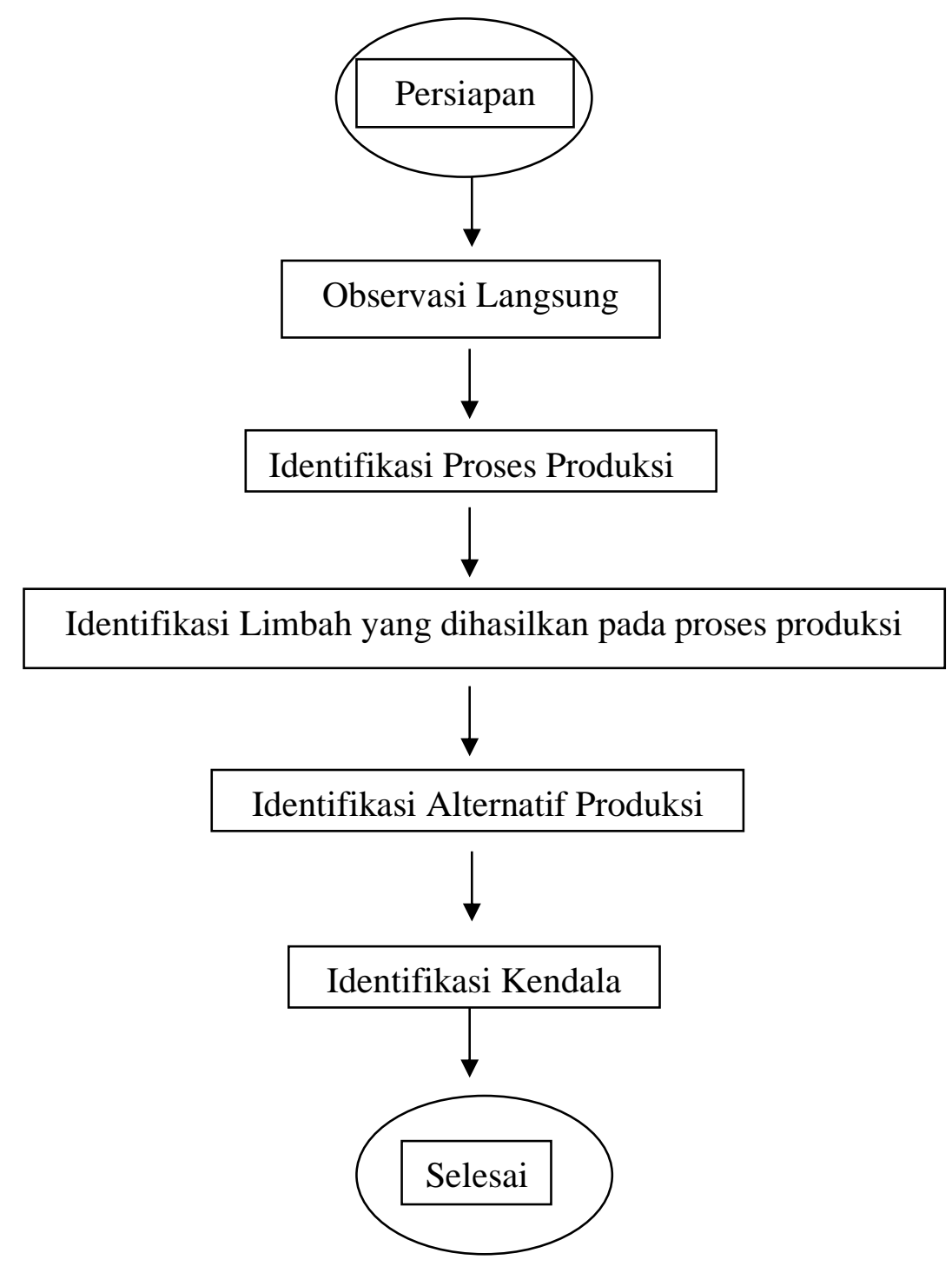

Gambar 1. Diagram Alir Tahapan Penelitian 


\section{HASIL DAN PEMBAHASAN}

\section{Kondisi Umum Industri}

Industri abon ikan tongkol khas pontianak pertama didirikan pada tahun 2012 berada di jalan Gusti Hamzah, gg. Pancasila IV, Kota Pontianak, Kalimantan Barat. Industri ini buka pada pukul 08.00-21.00 WIB. Abon Ikan Tongkol Khas Pontianak bisa didapatkan ada di Toko Happy Jalan Sisingamangaraja, Toko Isun Vera, Resto Mak Kundil Kobar, Resto Eyang. Jumlah produksi Abon ikan tongkol setiap hari sabtu dan minggu bisa mencapai 5$10 \mathrm{~kg}$ (tergantung pesanan). Selain untuk konsumsi di rumah, abon ikan tongkol juga praktis untuk bekal perjalanan jauh. Dengan kemasan menarik, abon ikan tongkol tersebut dijual dengan harga Rp.50.000 per 200 gram.

Proses pembuatan Abon ikan tongkol khas pontianak untuk sekali produksi yaitu :

1. Proses pemilihan ikan segar, kemudian dilakukan proses pemilahan seperti membuang kepala, ekor, kulit, dan isi perutnya, kemudian cuci; 5-10 kg ikan tongkol.

2. Kemudian dilakukan pengukusan ikan sampai matang, selanjutnya biarkan ikan tersebut dingin, supaya ikan menjadi kering masukkan ke dalam kain untuk ditekan dan disaring dengan mesin tekan (pers);

3. Pisahkan dari tulang dan durinya lalu suwir-suwir daging ikan, sehingga merupakan serat halus;

4. Panaskan dengan air mendidih sebanyak 10 liter, sambil diaduk-aduk

5. Masukkan suwiran daging ikan sedikit demi sedikit ke dalam wajan sambil diaduk terus sampai kering.

6. Proses penggorengan selesai apabila abon sudah merata keringnya, diraba untuk memastikan kering dengan sempurna, dan berwarna coklat. (Apabila masih banyak minyak, tekan dengan mesin tekan (press) dan tampung minyaknya);

7. Tiriskan dan dinginkan, kemudian masukkan ke dalam wadah plastik cup $200 \mathrm{gr}$ dan taburi bawang goreng, aduk-aduk hingga bawang goreng merata.

\section{Output/Limbah Yang Dihasilkan}

1. Pencucian

Luaran yang dihasilkan berupa air sisa cucian, kepala, kulit, dan isi perut ikan

2. Pengukusan

Luaran yang dihasilkan berupa air sisa hasil kukusan

3. Pemisahan daging dari tulang

Luaran yang dihasilkan berupa tulang ikan

4. Perebusan

Luaran yang dihasilkan berupa air sisa hasil rebusan

5. Penggorengan

Luaran yang dihasilkan berupa minyak goreng sisa

6. Pengemasan

Luaran yang dihasilkan berupa kemasan yang rusak 


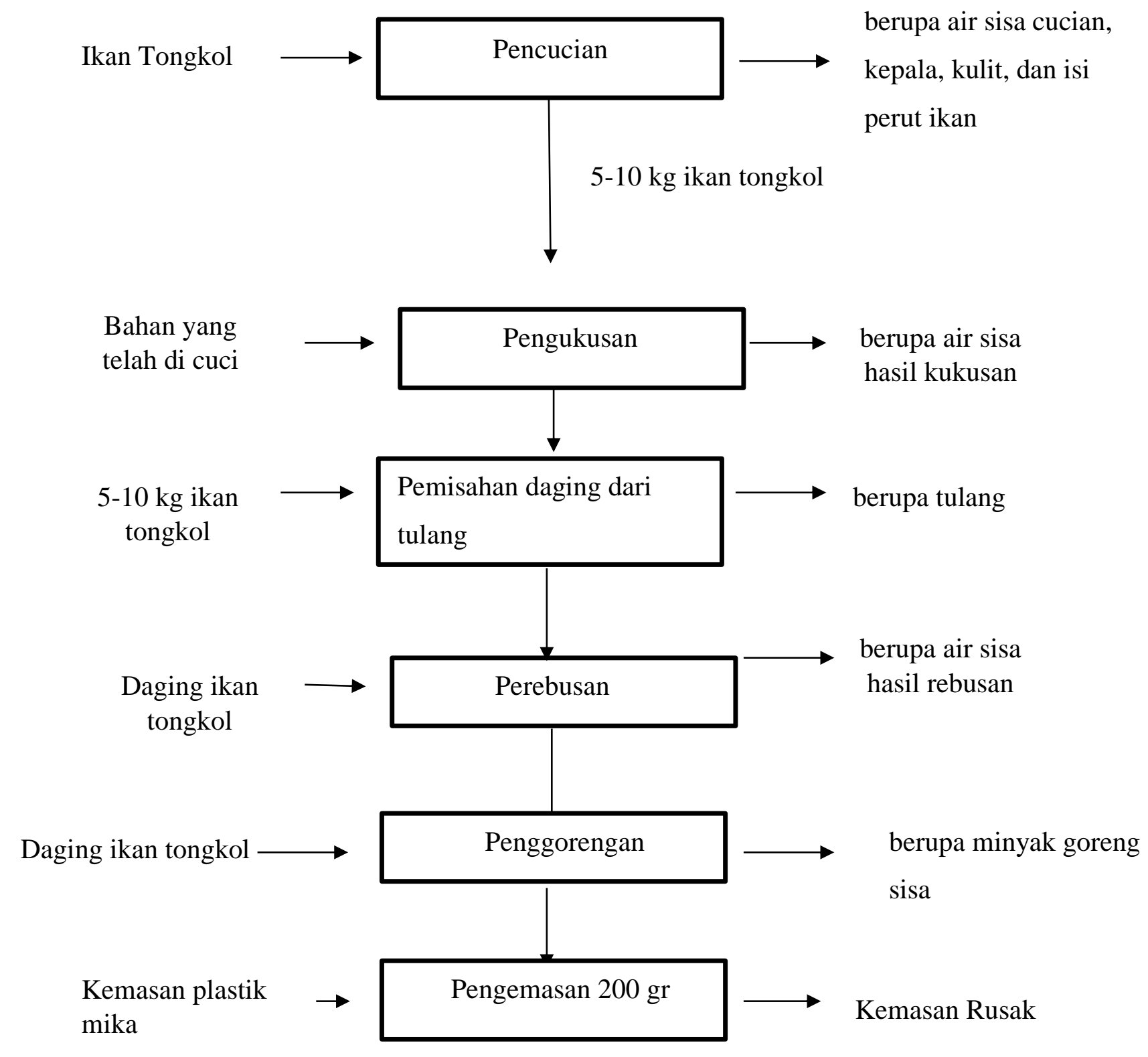

Gambar 2. Skema Proses produksi abon

\section{Alternatif Produksi Bersih}

\section{Pemanfaatan Limbah Tulang Ikan Tongkol Menjadi Tepung}

Tulang ikan mengandung sel-sel hidup dan matrik intraseluler dalam bentuk garam mineral. Garam mineral tersebut terdiri dari kalsium fosfat sebanyak $80 \%$ dan sisa sebagian besar terdiri dari kalsium karbonat dan magnesium fosfat $100 \mathrm{~cm}^{3}$ dari tulang yang mengandung $10.000 \mathrm{mg}$ kalsium. Tulang juga digunakan untuk menampung mineral lainnya (Frandson,1992 dalam Tababaka, 2004). Tepung dari tulang ikan merupakan suatu produk inovasi terbaru yang berbentuk padat kering yang dihasilkan dari beberapa proses panjang. 


\section{Proses Pembuatan Tepung dari Tulang Ikan Tongkol}

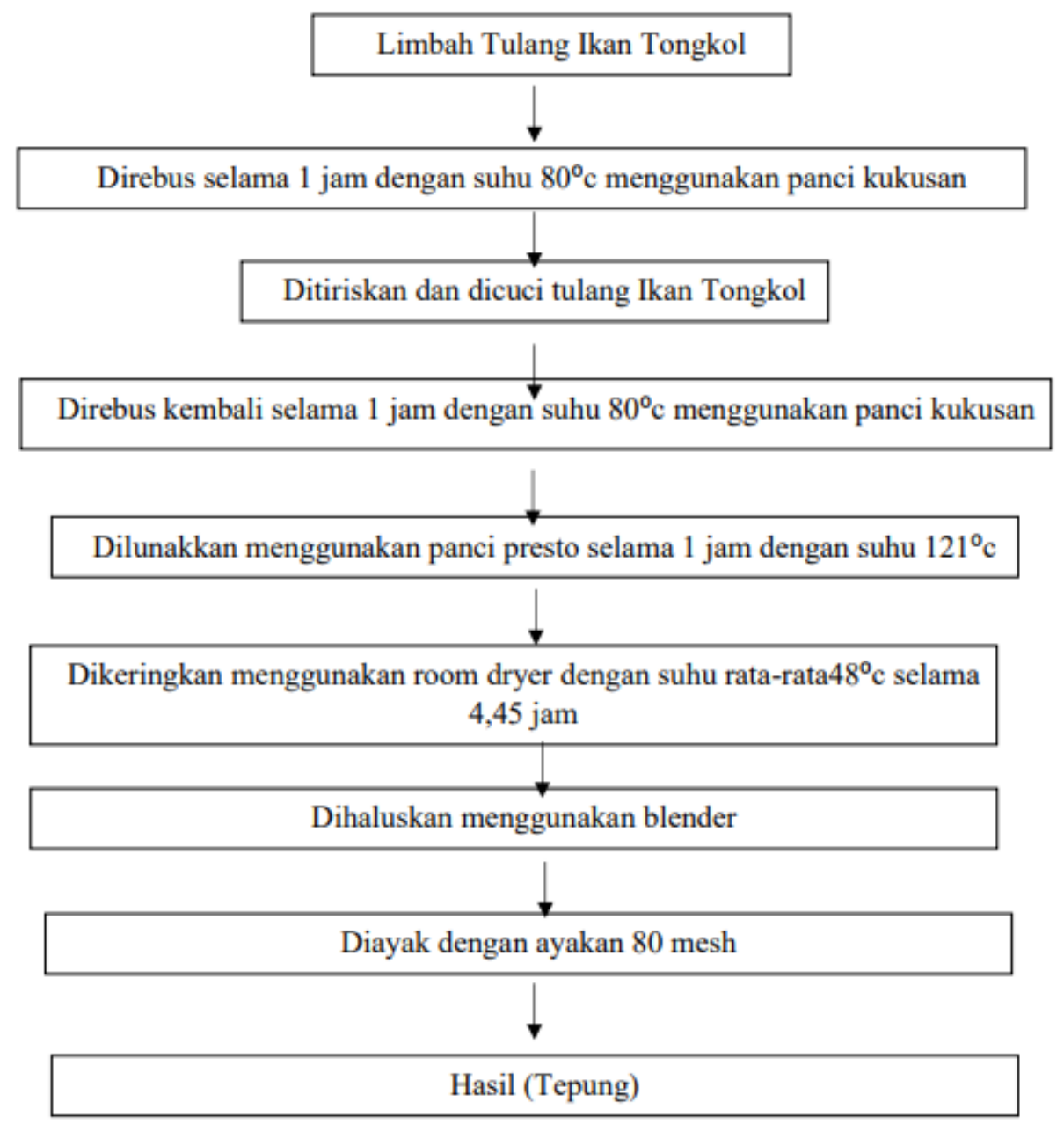

Gambar 3. Skema proses pembuatan tepung dari limbah tulang ikan tongkol

\section{PENUTUP}

Hasil produksi dari industri abon ikan tongkol akan menghasilkan limbah air bekas cucian, kepala ikan, isi perut ikan dan tulang. Inovasi yang bisa dilakukan untuk mengurangi limbah tersebut yakni pemanfaatan tulang ikan untuk dijadikan tepung sebagai produk alternatif dan ramah lingkungan.

\section{UCAPAN TERIMA KASIH}

Terima kasih kepada dosen pengampu mata kuliah Teknologi Bersih dan Minimasi Limbah Ibu Dian Rahayu Jati, S.T, M.Si dan Ibu Isna Apriani, S.T, M.Si serta pihak home industry abon ikan tongkol istimewa khas pontianak yang bersedia meluangkan waktu untuk ikut terlibat dalam proses penelitian dan penulisan jurnal ini. 


\section{DAFTAR PUSTAKA}

Alimusa, L. O., \& Murini, M. 2018 . ANALISIS NILAI TAMBAH PEMBUATAN ABON IKAN DALAM MENINGKATKAN PENDAPATAN EKONOMI RUMAH TANGGA DI KELURAHAN PURIRANO KEC. KENDARI KOTA KENDARI. Mega Aktiva: Jurnal Ekonomi Dan Manajemen.

Darmawangsyah, D., Jamaluddin, P.J.P., \& Kadirman, K. 2018 . FORTIFIKASI TEPUNG TULANG IKAN BANDENG (Chanos chanos) DALAM PEMBUATAN KUE KERING. Jurnal Pendidikan Teknologi Pertanian.

Dewi, Eko Nurcahya., Maysa Parmawati., \& Ratna Ibrahim. 2012. KUALITAS ABON IKAN TONGKOL (Euthynnus Affinis Cantor) YANG DIPROSES SECARA DEEP FRYING DAN PAN FRIYING SELAMA PENYIMPANAN PADA SUHU KAMAR. Universitas Diponegoro. Jawa Tengah.

Deswita, Nurul Chintya., \& Evi Fitriyani. 2019. KADAR KALSIUM DAN MUTU HEDONIK DONAT YANG DITAMBAHKAN TEPUNG KALSIUM TULANG IKAN TONGKOL (Euthynnus Affinis Cantor). Politeknik Negeri Pontianak.

Murniyati, AS., \& Sunarman. 2000. PENDINGINAN, PEMBEKUAN DAN PENGAWETAN IKAN. Kanisius. Yogyakarta.

Pratama, Rusky Intan., Iis Rostini., \& Evi Liviawaty. 2014. KARAKTERISTIK BISKUIT DENGAN PENAMBAHAN TEPUNG TULANG IKAN JANGILUS (Istiophorus Sp.). Univesitas Padjadjaran,

Suad, Abdurrahman., \& Kristina Novalina. N. 2019. STUDI KANDUNGAN KALSIUM PADA TEPUNG TULANG IKAN TONGKOL (Euthynnus Affinis Cantor) DAN TENGGIRI (Scomberomorus commerson). Politeknik Negeri Pontianak,

Sa'adah,Umi. 2013. NASKAH PUBLIKASI : DAYA TERIMA DAN KOMPOSISI PROKSIMAT TEPUNG TULANG IKAN LELE YANG MENGALAMI PROSES PERENDAMAN DALAM LARUTAN JERUK NIPIS. Universitas Muhammadiyah Surakarta. Surakarta.

Wicaksono, Ariq Suryo., Noor Harini., \& Warkoyo. 2017. UTILIZATION OF TONGKOL FISH (Euthynnus Affinis Cantor) BONE AS GELATIN (STUDY OF CHLORIDE ACID CONCENTRATION AND IMMERSION TIME). Universitas Muhammadiyah. Malang.

Sanger, Grace. 2010. OKSIDASI LEMAK IKAN TONGKOL ASAP YANG DIRENDAM DALAM LARUTAN EKSTRAK DAUN SIRIH. Universitas Sam Ratulangi. 